\title{
Interface fracture behavior of electroplated coating on metal substrate under compressive strain
}

\section{Kai Zhang*, Kun Zhang, Huai Xue Li, Guang Nan Chen}

Institute of Mechanics, Chinese Academy of Sciences, Beijing 100080, China

\section{A R T I C L E I N F O}

\section{Article history:}

Received 25 September 2006

Received in revised form

19 March 2008

Accepted 24 March 2008

Keywords:

Electroplated coating

Interface fracture

Compressive strain

T-bend test

\begin{abstract}
A B S T R A C T
The inducement of interface fracture is crucial to the analysis of interfacial adhesion between coating and substrate. For electroplated coating/metal substrate adhering materials with strong adhesion, interface cracking and coating spalling are difficult to be induced by conventional methods. In this paper an improved bending test named as T-bend test was conducted on a model coating system, i.e. electroplated chromium on a steel substrate. After the test, cross-sections of the coated materials were prepared to compare the failure behaviors under tensile strain and compressive strain induced by T-bend test. And the observation results show that coating cracking, interface cracking and partial spalling appear step by step. Based on experimental results, a new method may be proposed to rank the coated materials with strong interfacial adhesion.
\end{abstract}

(C) 2008 Elsevier B.V. All rights reserved.

\section{Introduction}

Coatings protect substrates from wear, high temperature degradation and corrosion. And a coating is functional only if the interface between coating and substrate is sound. So the evaluation of the interfacial adhesion is an important fundamental parameter, which determines whether the coating remains in place for the lifetime of the coating/substrate system in its operating environment. It is reported that there are more than 300 methods to evaluate the adhesion between coating and substrate (Mittal, 1995). During most of these methods, interface fracture was interpreted as an indication of unsatisfactory adhesion. However, for the strong interfacial adhesion of electroplated coating/metal substrate composite systems, interface cracking and coating spalling are difficult to be induced by convention methods such as tensile test
(Agrawal and Raj, 1988), scratch test (Bull and Berasetegui, 2006), indentation test (Li et al., 2002) and direct pull-off test (Rickerby, 1996).

In the present study, T-bend test improved was conducted on the electroplated chromium coatings on steel substrates which are typical electroplated coating/metal substrate composite systems with strong adhesion and have been widely used in various industries. In fact, many other bending tests had been conducted to evaluate the interfacial adhesion such as three-point bend test and four-point bend test. During these bend tests coatings were under tensile strain or compressive strain. But the strains could not induce the interface cracking of $\mathrm{Cr} / \mathrm{Fe}$ composite systems above-mentioned, especially for thin coating with a strong interface (coating thickness $<10 \mu \mathrm{m})$. During the T-bend test, severe compressive strain could induce the interface cracking. And the value of compres-

\footnotetext{
* Corresponding author.

E-mail addresses: kaizhang@imech.ac.cn (K. Zhang), kzhang@imech.ac.cn (K. Zhang). 0924-0136/\$ - see front matter @ 2008 Elsevier B.V. All rights reserved. doi:10.1016/j.jmatprotec.2008.03.036
} 


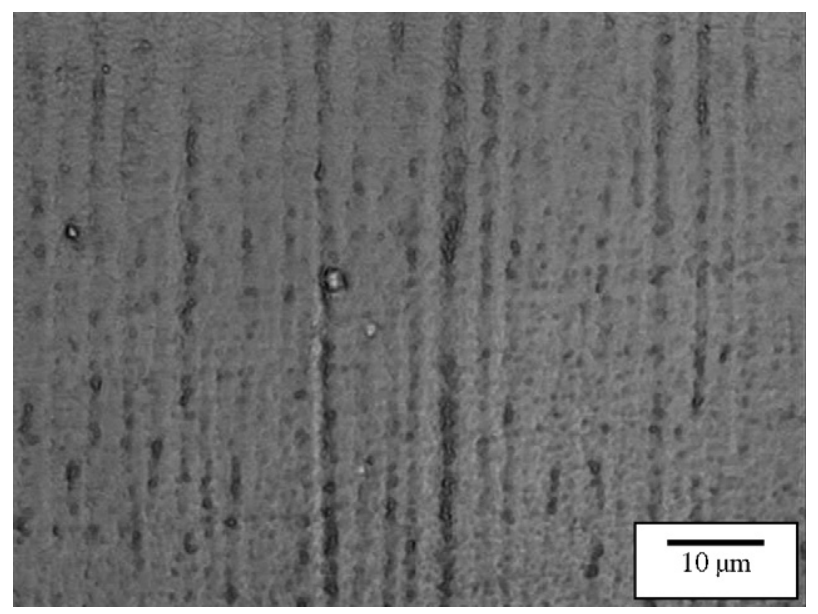

Fig. 1 - Optical micrograph of the coating surface.

sive strain could be used to rank the strong adhesion between electroplated coating and metal substrate.

\section{Experimental procedure}

\subsection{Specimen preparation}

The substrates were ASTM-1030 steel plates with a hardness of $168 \mathrm{HV}_{0.05 \mathrm{~kg}}$. The plates dimensions were $60 \mathrm{~mm} \times 2 \mathrm{~mm} \times 10 \mathrm{~mm}$. Before deposition, the substrates were mechanically polished to $0.06-0.10 \mu \mathrm{m}$ surface roughness. Cr coatings with thickness of $7 \mu \mathrm{m}$ were electrodeposited with a bath containing $\mathrm{CrO}_{3}(250 \mathrm{~g} / \mathrm{L}), \mathrm{H}_{2} \mathrm{SO}_{4}(2.5 \mathrm{~g} / \mathrm{L})$, and a few rare earth compounds. The deposition current density was $35 \mathrm{~A} / \mathrm{dm}^{2}$ and the temperature was $55^{\circ} \mathrm{C}$.

The hardness of the electroplated $\mathrm{Cr}$ coatings was determined using a microhardness indenter with a load of $10 \mathrm{~g}$ by $10 \mathrm{~s}$, and the value was $703 \mathrm{HV}$. The surface and cross-section morphology can be seen in Figs. 1 and 2

\subsection{Bending}

Fig. 3 is a schematic diagram of the T-bending test. At first, a specimen was bent by four-point bending test, which protect the investigated coating from being crushed by the crosshead found in three-point bending test. And the coating was on the compressive side (or the tensile side) of the specimen. Then a spacer was put inside the bent sheet and the sheet was pressed by press machine with block die to an angle of $180^{\circ}$ at the block die speed of $5 \mathrm{~mm} / \mathrm{min}$. The test was performed at $30^{\circ} \mathrm{C}$. The

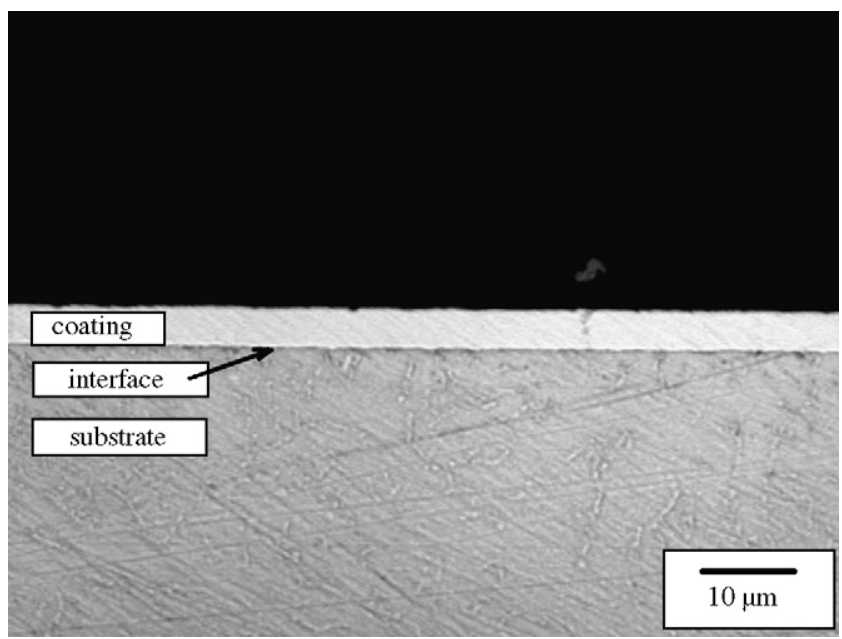

Fig. 2 - Optical micrograph of the cross-section.

strain of the coating or the interfacial region was calculated by the thickness of the spacer. The central zone of the sheet bent was examined with an optical microscope to identify the interfacial cracks.

\section{Results and discussion}

\subsection{Strain during T-bend test}

At first, the compressive strain during the test is discussed as follows.

The cross-section shape of the bent area can be described as a semi-circle and the centre of the sheet in the direction of thickness is neutral, which is not strained, as shown in Fig. 4.

The curvature radius of the neutral plane, $R$, is described as

$R=\frac{1}{2}(T+t)$

And the curvature radius of the inside surface, $r$, is described as

$r=\frac{1}{2} \mathrm{~T}$

Then the compressive strain of the inside surface of the coated sheet can be described as

$\varepsilon=\frac{2 \pi r-2 \pi R}{2 \pi R}$

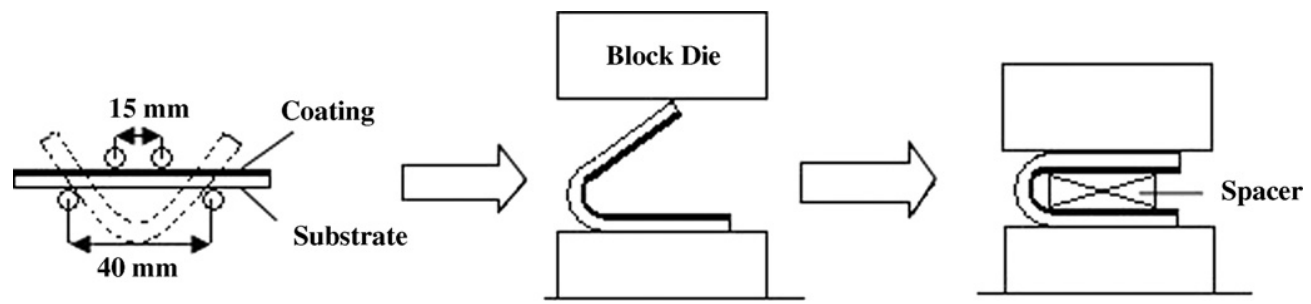

Fig. 3 - Procedure of T-bend test, and the coating was on the compressive side. 


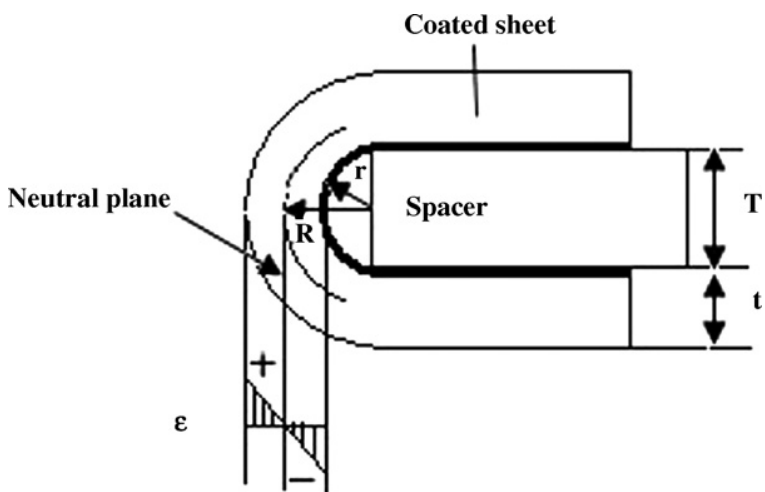

Fig. 4 - Schematic diagram of cross-section of bent part of coated sheet: $r$, curvature radius of the inside surface of the sheet; $R$, curvature radius of neutral plane of the coated sheet; $\varepsilon$, strain; $t$, thickness of the sheet; $T$, thickness of the spacer.

When the coating is put on the inside surface, $\varepsilon$ is also the compressive strain of the coating or the interfacial region inside, because the thickness of the coating can be neglected in the calculation.

Then substituting Eqs. (1) and (2) for Eq. (3), we can obtain the compressive strain on the inside surface as

$\varepsilon=-\frac{t}{T+t}$

In fact, Kohei had used the same model to lead the tensile strain on the outside surface as

$\varepsilon=\frac{t}{T+t}$

And he found that the strain values almost corresponded with the measured strain (Kohei et al., 2001).

From the above-mentioned equations, we found that the relationship between the compressive strain and the tensile strain is opposite. So we can use calculated strain to discuss the relationship between T-bend test and the coating failure.

In this study, 12 specimens which fixed the coatings on the compressive side were bent with 12 different spacers varying

\section{Table 1 - The compressive strain with different spacer}

Thickness of spacer $(\mathrm{mm})$

Compressive strain

\begin{tabular}{lrl}
\hline 1 & 15 & $-11.8 \%$ \\
2 & 14 & $-12.5 \%$ \\
3 & 13 & $-13.3 \%$ \\
4 & 12 & $-14.3 \%$ \\
5 & 11 & $-15.4 \%$ \\
6 & 10 & $-16.7 \%$ \\
7 & 9 & $-18.2 \%$ \\
8 & 8 & $-20.0 \%$ \\
9 & 7 & $-22.2 \%$ \\
10 & 6 & $-25.0 \%$ \\
11 & 5 & $-28.6 \%$ \\
12 & 4 & $-33.3 \%$ \\
\hline
\end{tabular}

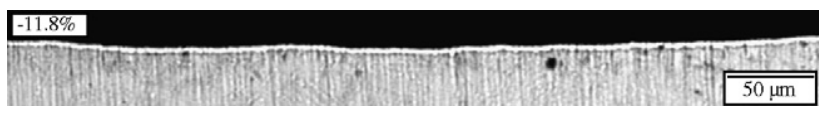

Fig. 5 - The morphological characteristics of cross-section under the compressive strain of $-11.8 \%$. It shows that the coating was curved after T-bend test.

from $4 \mathrm{~mm}$ to $15 \mathrm{~mm}$. Table 1 shows the values of compressive strain with different spacers applied in this study.

The other 12 specimens which fixed the coatings on the tensile side were bent with the same spacers shown in Table 1. From Eqs. (4) and (5) we can find that the absolute values of tensile strain and compressive strain are same with the same spacer, but the values of tensile strain are plus, rather than minus.

\subsection{Failure of the coatings under different strains}

The morphological characteristics of cross-section of the coatings on compressive side were investigated after T-bend test, and the result was shown in Figs. 5 and 6 .

As soon as the compressive strain was increased up to $-16.7 \%$, the cracks in the coating initiated and propagated so rapidly to the interface, and these cracks formed some sloping sides which can act like a wedge. When the compressive strain was increased up to $-25.0 \%$, the compressive stress drove the coating up the wedge causing an interface crack. When the compressive strain was increased up to $-28.6 \%$, the interfacial crack propagated continually and the wedge lifted the coating further away from the substrate. When the compressive strain was increased up to $-33.3 \%$, large enough placement induced partial spalling of the electroplated chromium coating. Strictly
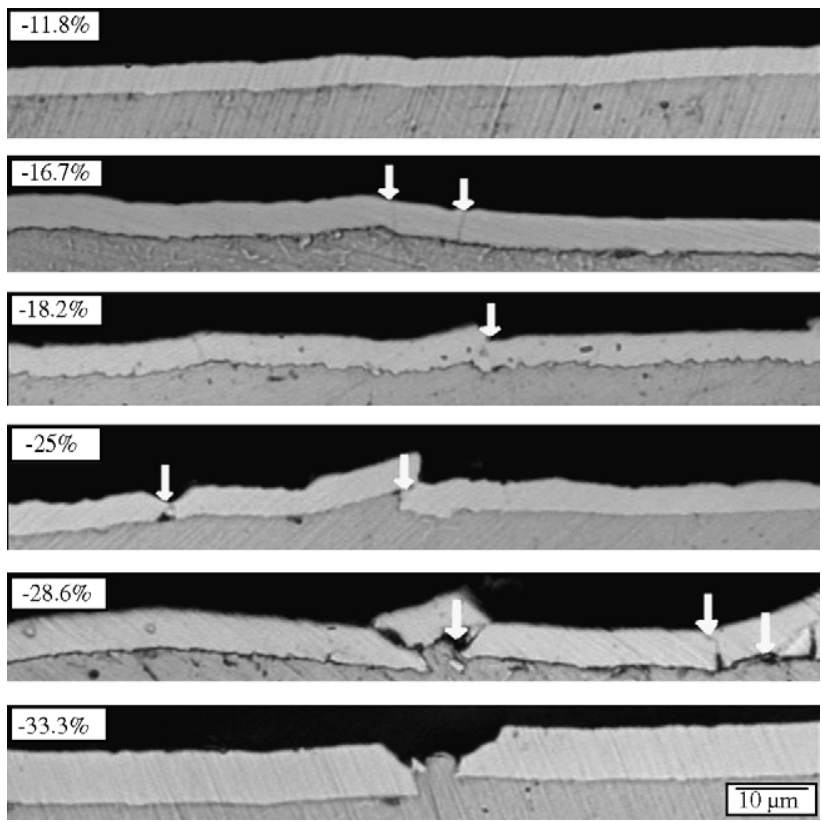

Fig. 6 - The morphological characteristics of cross-section under different compressive strain. Arrows in the images denote the position of cracks. Numerals in the images show the applied compressive strain in percentage. 


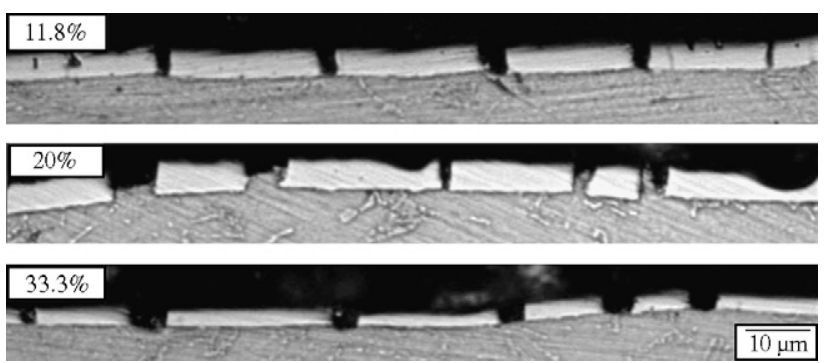

Fig. 7 - The morphological characteristics of cross-section under different tensile strain led by T-bend test. Numerals in the images show the applied tensile strain in percentage.

speaking, the said interface cracking represent the cracking occurred in the interfacial region or interphase, because the interface is a mathematical plane or a sharp frontier with no thickness.

Generally speaking, the plastic properties of the coating and the substrate are different, and their plastic deformations cannot correspond with each other under compressive strain, which is well-known as "mismatch". The mismatch between the plastic zone of the brittle coating and the ductile substrate increases with compressive strain increasing until a critical cracking point is reached, at which interface cracking initiates, propagates and finally results in coating spalling to release the energy stored in the coating and the interfacial region.

The morphological characteristics of cross-section of the coatings on tensile side were investigated too, and the result was shown in Fig. 7.

Under the tensile strain, a number of macrocracks tended to initiate and penetrate through the coating, and then stopped at the interface. And the width of cracks tended to increase with the progressive applied tensile loading. The vertical cracks should be attributed to the relief of effective energy associated with the mismatch induced by tensile strain. And there was no interfacial crack observed on the tensile side, because the coating-subsrate bond was strong compared with the coating cohesion. These results corresponded with the result of tensile test conducted in our previous work, and the result was shown in Fig. 8.

From the observation results we can conclude that the main failure under compressive strain is delamination, and the main failure under tensile strain is segmentation. Segmentation is defined as a network of cracks starting from the top surface of the coating that propagate in a direction perpendicular to the interface. Delamination involves initiation and growth of cracks at the coating-substrate interface.

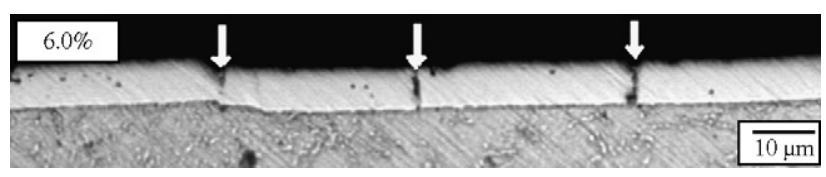

Fig. 8 - The morphological characteristics of cross-section after tensile test. Arrows in the images denote the position of cracks. Numerals in the images show the applied tensile strain in percentage.
Based on the observation results, we found that although these specimens were prepared with the same process, the thicknesses of coatings were not identical. It should be pointed out that they were all in an acceptable range which must not deny the correctness of the analysis above-mentioned.

In fact, T-bend test had been applied to evaluate the formability of steel sheets as a standard test (GB/T 15825.5-1995). But it evaluates the formability by tensile strain, which cannot induce the interface cracking of the $\mathrm{Cr} / \mathrm{Fe}$ composite systems as above-mentioned segment. So it failed to evaluate the interfacial adhesion under tensile strain but compressive strain. But in our previous work, it failed to separate the interface of $\mathrm{Cr} / \mathrm{Fe}$ composite systems by three-point bend test and four-point bend test, because the compressive strain was too deficient to induce interface cracking. And the T-bend test above-mentioned can lead to severe compressive strain near the interface, which cannot be led by three-point bend test or four-point bend test. During previous works on cross-sectional indentation (Su et al., 2004), we also found that making severe plastic deformation near the interface is an effective way to induce the interface cracking.

Consequently, we improved T-bend test, and utilized severe plastic deformation to induce the interface cracking and coating spalling successfully. And the interfacial adhesion can be ranked by the compressive strain to which the specimen could be bent without interfacial crack. This method is useful for comparative purpose, and it can be taken as a crude measure to rank the strong interfacial adhesion of electroplated coating/metal substrate composite systems. Then we found that the breadth and thickness ratio of the specimen should be more than 5:1, but the specimen could not be less than $10 \mathrm{~mm}$ in breadth; the thickness of the specimens should be from $0.3 \mathrm{~mm}$ to $4.0 \mathrm{~mm}$; the length must be longer than $60 \mathrm{~mm}$. These demands in dimension will ensure the stability and veracity of the experimental process.

It is noticeable that the compressive strain obtained from the T-bend test is not the final parameter introduced by us to measure the interfacial adhesion. It is well-known that the strain is closely interrelated with the calculation of fracture energy of the coating/substrate interface or the interfacial region. And the fracture energy is an accredited scale used to describe the interfacial adhesion (Rickerby, 1996; Shaw et al., 1998). So the target of this study is to calculate the fracture energy by establishing a relationship between the compressive strain and energy. So the further mechanics analysis and the factors from coatings which may affect the results of $\mathrm{T}$ bend test will be the focus of our next work. And based on comparative experiments, we find one of the key factors is the thickness of the coatings. Increasing with the thickness of coatings the spacer used to make interface crack is thicker and the compressive strain needed to induce interface cracks is smaller. We are going to conduct a series of experiment to research above-mentioned result in our next paper.

\section{Conclusion}

The T-bend test is a test method with simple shape and loading style which can cause interface cracking successfully. During the test, if the coated sheet can suffer larger compres- 
sive strain without interface cracking, it should have stronger interfacial adhesion. And the compressive strain can be utilized to rank the interfacial adhesion of the electroplated coating/metal substrate adhering materials. Therefore, the Tbend test is a feasible technique to compare the interfacial adhesion of different coated materials.

\section{REFERENCES}

Agrawal, D.C., Raj, R., 1988. Measurement of the ultimate shear strength of a metal-ceramic interface. Acta. Metall. 37 (4), 1265-1270.

Bull, S.J., Berasetegui, E.G., 2006. An overview of the potential of quantitative coating adhesion measurement by scratch testing. Tribol. Int. 39, 99-114.

GB/T 15825.5-1995, Sheet metal formability and test methods.
Kohei, U., Hiroshi, K., Takamasa, S., Takeshi, A., 2001. Effects of mechanical properties of paint film on the forming of pre-painted steel sheets. Prog. Org. Coat. 43 (4), 233-242.

Li, H.Q., Cai, X., Ma, F., Chen, Q.L., 2002. Determination of the interfacial bonding strength of thin films and coating using indentation method. Mater. Mech. Eng. 26 (4), 11-22.

Mittal, K.L., 1995. Adhesion measurement of films and coatings: a commentary. In: Mittal, K.L. (Ed.), Adhesion Measurement of Films and Coatings. VSP, Utrecht, The Netherlands, pp. 1-13.

Rickerby, D., 1996. Measurement of coating adhesion. In: Stern, K.H. (Ed.), Metallurgical and Ceramic Protective Coatings. Chapman \& Hall, London, pp. 306-317.

Shaw, L.L., Barber, B., Jordan, E.H., Gell, M., 1998. Measurements of the interface fracture energy of thermal barrier coatings. Scripta Mater. 39 (10), 1427-1434.

Su, J.Y., Zhang, K., Chen, G.N., 2004. Evaluation of the interfacial adhesion between brittle coating and ductile substrate by cross-sectional indention. Trans. Mater. Heat Treat. 25 (5), 1187-1190. 